\title{
Criar Éducaçãa
}

\section{A PRÁXIS CAPOEIRANA E AS COMPETÊNCIAS HUMANAS: PROPOSTA PARA CONTAR SUA HISTORIA CORPORALMENTE LA PRAXIS CAPOEIRANA Y LAS COMPETENCIAS HUMANAS: PROPUESTA PARA CONTAR SU HISTORIA CORPORALMENTE}

\author{
VIEIRA, Marcelo Braz ${ }^{1}$ \\ SOUZA, Edison Roberto de ${ }^{2}$
}

Resumo: Este artigo busca compartilhar uma experiência desenvolvida com a capoeira num projeto de educação através do esporte realizada nas imediações de uma Universidade pública brasileira onde o objetivo principal era a sua utilização como ferramenta educativa de desenvolvimento humano desde uma perspectiva das competências humanas. Nesta direção, se descreve as etapas de sua construção divididas em: "tecendo a rede", "as redes da rede", "re-significação da rede", "representar os papeis", "a roda da liberdade" e "a roda da vida" e seus respectivos significados na formação das competências humanas (competência pessoal, produtiva, social, cognitiva e motora) juntamente com o aprendizado histórico e corporal da capoeira, manifestação da cultura brasileira.

Palavras-chave: Capoeira. Competências humanas. História. Corpo.

Resumen: Este artículo pretende compartir una experiencia desarrollada con la capoeira en un proyecto de educación a través del deporte que tuvo lugar en las inmediaciones de una universidad pública brasileña. El principal objetivo era su utilización como herramienta educativa para el desarrollo humano desde la perspectiva de las competencias humanas. En este sentido, se describen las etapas de su construcción dividida en "construyendo la red", "redes de la red", "redefiniendo la red", "representación de las funciones", "la libertad de la rueda" y "la rueda de la vida". Y también sus significados en la formación de competencias humanas (competencia personal, productiva, social, cognitivas y motriz) en conjunto con aprendizaje histórico y corporal de la capoeira, manifestación de la cultura brasileña.

Palabras clave: Capoeira. Competencias humanas. Historia. Cuerpo.

\footnotetext{
1 Doutorando em Actividad Física, Educación Física y Deporte na Universidad de Barcelona. marcelobraz@ub.edu

2Doutor em Mídia e Conhecimento pela Universidade Federal de Santa Catarina (UFSC); Mestre em Educação pela PUC-RS; Profo do Departamento do Curso de Educação Física da UFSC. edsonroberto@cds.ufsc.br
} 


\section{Criar Êducação}

\section{ORIGEM DA PROPOSTA}

Com a responsabilidade de estimular o desenvolvimento humano de crianças participantes do Projeto de Educação pelo Esporte "Brinca Mané", desenvolvido entre a Universidade Federal de Santa Catarina (UFSC) e o Instituto Ayrton Senna, entre abril de 2003 até dezembro de 2009, a oficina de capoeira utilizada como ferramenta educativa teve seu destaque no anseio de construir uma proposta inovadora e contextualizada com a sua própria história, manifestação popular lúdica, cultural e de expressão corporal, envolvendo dança, arte, música, luta, jogo e esporte.

O projeto "Brinca Mané" buscou através do esporte educativo, contribuir no desenvolvimento das competências humanas de seus participantes. Participavam do projeto duzentas crianças na faixa etária entre sete (7) e quinze (15) anos, oriundas de escolas públicas circunvizinhas à UFSC, separadas por turmas de acordo com suas idades, no contra turno do período de aula.

Os conteúdos condutores das ações desenvolvidas neste projeto foram fundamentados no Relatório da Comissão Internacional sobre Educação para o Século XXI, da UNESCO, organizado por Jacques Delors (1999) que trata sobre o conceito de desenvolvimento humano e dos quatros pilares da educação. Considerando que cada criança tem um potencial a ser descoberto e que a educação é um dos caminhos para atingi-los, esses quatro pilares e suas respectivas competências, ao serem fomentados podem auxiliar no desenvolvimento e na conquista das suas potencialidades, que permitirão a sua inserção na sociedade.

Para a progressão dessas competências, o projeto "Brinca Mané" realizou dentro de uma proposta pedagógica em forma de oficinas específicas (jogos e esportes; natação; orientação à saúde; arte-educação) oportunizando o desenvolvimento de atividades diversificadas, tendo a corporeidade e a ludicidade como elementos centrais na busca da aquisição dos objetivos propostos, proporcionando às crianças um ambiente favorável, prazeroso, significativo, concreto e complementar a sua formação. E como dito anteriormente, uma destas oficinas foi a capoeira, objeto deste estudo que visa compartilhar o resultado de um 


\section{Criar Éducaçãa}

trabalho realizado dentro de um contexto de formação de educadores num encontro especifico do instituto fomentador deste programa educativo.

\section{PILARES DAS COMPETÊNCIAS HUMANAS}

Pensando na disseminação de tecnologia da educação social e o desenvolvimento humano, se requer a reflexão e o entendimento sobre quais são os quatros pilares da educação e as suas respectivas competências, pois estes foram os eixos condutores da ação realizada no projeto "Brinca Mané": Aprender a Ser (Competência Pessoal); Aprender a Conviver (Competência Social); Aprender a Fazer (Competência Produtiva); Aprender a Conhecer (Competência Cognitiva) (DELLORS, 1999; HASSENPLUG, 2004). Uma quinta dimensão foi inserida na referida reflexão, se trata do aprender a se mover, da competência motora (SOUZA, MATOS, 2008).

Aprender a Ser (Competência Pessoal) a integração de todas as competências, se desenvolve pela melhoria contínua da personalidade, das características individuais, da autonomia e da responsabilidade pessoal que se reflete na relação com as outras pessoas e com o ambiente. A aprendizagem precisa ser integral, não negligenciando nenhuma das potencialidades de cada indivíduo.

Aprender a Conviver (Competência Social) caracteriza-se pelo aprender a viver em grupo, um importantíssimo aprendizado por ser valorizado quem aprende a viver com os outros, a compreendê-los, desenvolvendo a compreensão do outro e a percepção da interdependência, a administrar conflitos, a participar de projetos comuns, a ter prazer no esforço comum, no respeito pelos valores do pluralismo, da compreensão mútua e da paz.

Aprender a Fazer (Competência Produtiva), esta relacionada ao preparar-se com para inserção no mercado laboral, a fim de adquirir, não somente uma qualificação profissional, mas de uma maneira mais ampla, descobrir as habilidades para fazer, é agir sobre algo com qualidade, competências que tornem a pessoa apta a enfrentar numerosas situações e a trabalhar em equipe.

Aprender a Conhecer (Competência Cognitiva) é a necessidade de descobrir o que precisamos para aprender combinando uma cultura geral, suficientemente 


\section{Criar Éducação}

vasta, com a possibilidade de trabalhar em profundidade um pequeno número de matérias. É necessário tornar prazeroso o ato de compreender, descobrir, construir e reconstruir o conhecimento que também significa: aprender a aprender, para beneficiar-se das oportunidades oferecidas pela educação ao longo de toda a vida, pensando no novo, reconstruindo o velho e reinventando o pensar.

.Aprender a Se Mover (Competência Motora) é a organização e utilização da motricidade da criança de forma adequada e significativa transcendendo as necessidades biológicas e sendo desenhado na perspectiva do desabrochar atitudes de cooperação, solidariedade, dignidade e respeito, de promover o espírito criativo, imaginativo e construtivo, de interação com o outro e com o mundo, etc...;

\section{A PRAXIS CAPOEIRANA: A HISTÓRIA CONTADA ATRAVÉS DO CORPO}

Realizando apenas um repasso histórico da capoeira neste estudo, por se tratar de uma proposta em que o ministrante deve ter um conhecimento prévio relacionado a esta cultura, se pode destacar como muito importante e fundamental para o desenvolvimento da proposta os fatos a seguir expostos.

Desembarcados no Brasil por volta de 1548 e, nos três séculos seguintes, os escravos africanos eram predominantemente do tronco linguístico banto, do qual faz parte à língua quimbundo, englobando angolas, benguelas, moçambiques, cabindas e congos. Eram povos de pequenos reinos, com um razoável domínio de técnicas agrícolas e cuja grande característica era possuir uma visão muito plástica e imaginosa da vida, com grande capacidade de adaptação cultural. Esses grupos étnicos, rivais na África, em virtude da escravidão a que foram submetidos no Brasil, se uniram formando uma cultura africana que plantou bases muito fortes na cultura brasileira, de dança, música e técnicas de corpo como a capoeira. Sua importância histórica, segundo Areias (1984), se dá por ser um conjunto de expressões que contam a história do povo negro no Brasil, povo que lutou pela liberdade, dignidade e cidadania.

Em seu momento inicial a capoeira tinha como objetivo, a defesa pessoal, pois os escravos fugidos lutavam pela sobrevivência contra os temidos ataques dos capitães do mato. Após a abolição da escravatura, a finalidade da capoeira passa a 
ser um modo de sobrevivência dos "ex-escravos", que não tinham condições dignas de sobrevivência e utilizavam suas destrezas para saquear lojas e as casas dos senhores. A partir desta fase a capoeira foi proibida por Lei e teve um declínio em suas manifestações, apesar de ser praticada às escondidas. Mais adiante, na segunda metade do século XIX, a capoeira já era praticada por diferentes tipos sociais: escravos, livres, libertos, africanos, descendentes de africanos, militares, portugueses, imigrantes europeus e, inclusive, membros da elite social (CUNHA, VIEIRA, TAVARES, SAMPAIO, 2014; LUSSAC, TUBINO, 2009).

Atualmente, além do Brasil, a capoeira está presente em mais de 150 países e juntamente com o samba e o futebol, é parte da identidade cultural do Brasil (VIEIRA, 2002), sendo a roda de capoeira reconhecida como Patrimônio Cultural Imaterial da Humanidade. Outro fator que vem contribuindo para esta popularização ocorre pelos inúmeros estudos, nas mais diversas áreas do conhecimento humano, como a antropologia, a sociologia, a pedagogia, a educação física, a psicologia, a biomecânica, a história e as artes (D'AGOSTINI 2003; VIEIRA, ASSUNÇÃO, 2009).

As atividades aqui propostas foram reconstruídas e atribuídas novas dimensões de atividades já existentes, descritas por REIS (1997) e por FREITAS (2003). Estas atividades utilizam os valores relacionados às competências humanas, mais especificamente enfocadas no pilar aprender a ser, entendendo que este é a integração das demais competências, oportunizando aos participantes através das vivências, conhecer e experimentar corporalmente fatos da história da escravidão no Brasil. Cada atividade consiste num momento pratico e num momento histórico que é contextualizado ao final de toda a oficina.

Tecendo a Rede é atividade inicial que onde se propõe um alongamento coletivo. Os participantes dispostos em circulo e de mãos dadas devem sem se comunicar, andar para qualquer direção sem solar as mãos até que não seja mais possível caminhar. Então todos devem retornar ao local inicial, ainda de mãos dadas e sem conversar. Ao escolher qual direção seguir, se oportuniza aos participantes a associação do valor da atividade, pois esta possui como intuito conscientizá-los de que a direção escolhida por um deverá ser seguida pelos demais, justamente como aconteciam com os escravos na chegada ao Brasil, em que todos amarrados tinham que andar na mesma direção, além de impossibilitados de se comunicarem;

UNESC, Criciúma, v. 5, ำ1, janeiro/Junho 2016. Criar Educação - PPGE - UNESC 


\section{Criar Éducaçãa}

As Redes da Rede constitui-se em atividades separadas em grupos menores. Nesta segunda atividade nas quais os participantes devem realizar movimentos da época da escravidão no Brasil, como: imitar as atividades realizadas num Canavial; num Cafezal; imitar uma Moagem de Cana; realizar atividades da Casa do Senhorio; realizar ocorrências no Tronco, com o Chicote do Feitor. Aos participantes são proporcionados momentos de reflexões críticos e autônomos sobre a condição na qual os negros eram condicionados a realizarem tarefas obrigatórias e receberem castigos;

Re-significação da Rede, esta atividade visa ilustrar aos participantes o momento que os negros iniciam uma nova linguagem, já que na sua chegada, a sua distribuição teve foi organizada afim de separá-los em grupos de diferentes dialetos, evitando assim o diálogo e a provável rebelião. Deste modo, a atividade transcorre em círculo de maneira que todos cantam o nome das pessoas numa língua especial, o "lalaue", uma cantiga típica das rodas de capoeira. A música "lallaue" é cantada da seguinte forma laaaa laauee lauee lauee lauaa e na atividade, a mesma é substituída pelo nome dos integrantes da roda (Ex. Marcelo - maaa mama mama marce lolo), devendo ser repetida por todos e cantada todos os nomes dos participantes, contribuindo assim para o aumento da auto-estima dos participantes;

Representar os Papéis consiste em um jogo de pega, no qual existem "os feitores" que devem capturar "os escravos fugidos". O feitor atribuirá ordens (exercícios realizados em "As Redes da Rede") aos escravos capturados que deverão manter-se realizando a mesma até serem salvos, ou seja, recebendo um abraço salvador de outro escravo, quando poderão volta a corre. Esta representação tem o intuito de instigá-los, pois o ministrador da atividade deve verificar quem tem o instinto de mandar, para iniciar no papel de feitor, realizando troca de papeis após um determinado momento. Este momento da história do negro, esta ligada à tentativa de fugas das casas dos feitores, que utilizavam os capitães de mato para capturar estes escravos fugitivos. Nessas fugas se formavam os quilombos para a proteção contra aqueles que lhes perseguiam. A atividade repercutirá a valorização da vida nos participantes, após vivenciarem estes momentos já vividos por seres humanos;

UNESC, Criciúma, v. 5, ํ1, janeiro/Junho 2016. Criar Educação - PPGE - UNESC 


\section{Criar Éducaçãa}

A Roda da Liberdade é a roda de capoeira propriamente dita, com a ressalva de que os movimentos autônomos realizados durante as atividades poderão ser utilizados, isto é, os movimentos construídos por cada participante sem a necessidade das características da capoeira como se conhece. Assim, a roda de capoeira poderá ser vivenciada por todos, mesmo os que dizem não serem capazes de realizar tais movimentos, atingindo novamente a auto-estima dos participantes. Explica-se que a capoeira atual é reconstruída a cada momento e que ela pode ser jogada de forma simples e agradável, dependendo apenas do objetivo da mesma.

A Roda da Vida é o momento de contextualização das atividades. Esta roda surgiu da rotina do Projeto onde se realizava uma roda pedagógica ao inicio e ao final de cada atividade, buscando informar o que seria realizado e avaliar a mesma. Assim, na "roda da vida" todas as atividades desenvolvidas serão relacionadas com a história da escravidão no Brasil, justificá-las e também contribuindo para o crescimento dos valores do pilar Aprender a Ser em cada participante.

\section{ALGUMAS REFLEXÕES FINAIS}

Como explicado no início desde estudo, o mesmo visa o compartilhamento de uma experiência com atividades desenvolvidas num contexto educativo com crianças. Ao se tratar de uma proposta pedagógica do movimentar-se da criança no contexto específico da capoeira, é urgente que se desenvolvam mais conhecimentos sobre os efeitos desta manifestação da cultura corporal brasileira enquanto ferramenta educativa. Toda a proposta contextualiza-se a partir da história dos negros e da capoeira tornando-se o tema de cada uma das diversas fases da atividade.

Além da capoeira, se entende como fundamental, compreender as várias dimensões de desenvolvimento da criança. Refletir sobre sua complexidade e suas aspirações, talvez nos apontem trilhas que possa consolidar com mais concretude nossa proposta educativa de educação pela capoeira.

Principalmente por que a capoeira é uma arte aprendida tradicionalmente pela história e cultura oral dos negros e por ser um meio de expressão que envolve várias possibilidades de ação, como o jogo, a música, a dança, a luta e merece todo o cuidado em seu trato. Portanto, a preocupação neste estudo foi de apontar 


\section{Criar Éducaçãa}

possibilidades pedagógicas desta manifestação na busca, sobretudo de oportunizar as crianças, desenvolvimento de competências que certamente terão reflexos em várias dimensões de suas vidas, colaborando assim para a aquisição das competências humanas. Os objetivos da proposta buscou conscientizar os participantes sobre a relevância do esporte na promoção das competências humanas, através do vivenciar corporalmente a história da capoeira, compreendendo-a como uma excelente ferramenta educativa de desenvolvimento das competências humanas;

Portanto, a partir do trabalho desenvolvido no projeto "Brinca Mané" com esta manifestação da cultura popular brasileira, os resultados apontam para sua utilização como ferramenta para uma prática alternativa que oportuniza o desenvolvimento das competências humanas, e, paralelamente, desenvolve e estimula outras dimensões como: a ludicidade, a musicalidade, a espiritualidade, o prazer e a felicidade.

UNESC, Criciúma, v. 5, ํ1, janeiro/Junho 2016. Criar Educação - PPGE - UNESC 


\section{Criar Éducaçãa}

\section{REFERÊNCIAS BIBLIOGRÁFICAS}

AREIAS, A.. O Que é Capoeira. São Paulo: Ed. Brasiliense, 2003.

D'AGOSTINI, A.. $O$ jogo da Capoeira sob o contexto antropológico e biomecânico. Dissertação de Mestrado em Educação Física. UFSC. Florianópolis (SC), 2003.

CUNHA, I.M.C.F da; VIEIRA, L.R.; TAVARES, L.C.V.; SAMPAIO, T.M.V. Capoeira: a memória social construída por meio do corpo. Movimento V.20, n. 2, p. 735-755, 2014.

DELORS, J., et al. Educação Um Tesouro a Descobrir - Relatório para UNESCO da Comissão Internacional sobre Educação para o Século XXI. São Paulo: Cortez - Brasília (DF): MEC/UNESCO, 1999.

FREITAS, J.L. de. Capoeira Infantil: jogos e brincadeiras. Curitiba: Torre de Papel, 2003.

HASSENPLUG. Walderez Nosé. Educação pelo Esporte: Educação para o Desenvolvimento Humano pelo Esporte. São Paulo: Saraiva/Instituto Ayrton Senna, 2004.

LUSSAC, R.M.P.; TUBINO, M.J.G.. Capoeira: a história e trajetória de um patrimônio cultural do Brasil. Revista da Educação Física/UEM, v. 20, n. 1, p. 7-16, abr. 2009. REIS, A.L.T.. Brincando de Capoeira: recreação e lazer na escola. Brasília: Editora Valcy, 1997.

SOUZA, E. R.; MATOS, N.C. Aprender a se mover: no jogar, a construção do quinto pilar. In: SANTOS, S. L. C. (Org.). Projeto Social como divisor de águas: os valores transmitidos pelo projeto de educação pelo esporte na formação humana. Curitiba (PR): Coração Brasil Editora, 2008. p. 35-38.

VIEIRA, L.R.. A capoeira e a cultura internacional-popular. Revista Praticando Capoeira, São Paulo, n.18 set. 2002.

VIEIRA, L.R.; ASSUNÇÃO, M.R.. Os desafios contemporâneos da capoeira. Brasília: Ministério das Relações Exteriores, 2009. (Textos do Brasil, 14: Capoeira). 